\title{
Determinants of tick-borne encephalitis in counties of southern Germany, 2001-2008
}

\author{
Christian Kiffner ${ }^{1 *}$, Walter Zucchini ${ }^{2}$, Philipp Schomaker ${ }^{1}$, Torsten Vor ${ }^{1}$, Peter Hagedorn ${ }^{3}$, Matthias Niedrig ${ }^{3}$, \\ Ferdinand Rühe ${ }^{1}$
}

\begin{abstract}
Background: Tick-borne encephalitis (TBE) virus can cause severe symptoms in humans. The incidence of this vector-borne pathogen in humans is characterised by spatial and temporal heterogeneity. To explain the variation in reported human TBE cases per county in southern Germany, we designed a time-lagged, spatially-explicit model that incorporates ecological, environmental, and climatic factors.

Results: We fitted a logistic regression model to the annual counts of reported human TBE cases in each of 140 counties over an eight year period. The model controlled for spatial autocorrelation and unexplained temporal variation. The occurrence of human TBE was found to be positively correlated with the proportions of broad-leafed, mixed and coniferous forest cover. An index of forest fragmentation was negatively correlated with TBE incidence, suggesting that infection risk is higher in fragmented landscapes. The results contradict previous evidence regarding the relevance of a specific spring-time temperature regime for TBE epidemiology. Hunting bag data of roe deer (Capreolus capreolus) in the previous year was positively correlated with human TBE incidence, and hunting bag density of red fox (Vulpes vulpes) and red deer (Cervus elaphus) in the previous year were negatively correlated with human TBE incidence.

Conclusions: Our approach suggests that a combination of landscape and climatic variables as well as hostspecies dynamics influence TBE infection risk in humans. The model was unable to explain some of the temporal variation, specifically the high counts in 2005 and 2006. Factors such as the exposure of humans to infected ticks and forest rodent population dynamics, for which we have no data, are likely to be explanatory factors. Such information is required to identify the determinants of TBE more reliably. Having records of TBE infection sites at a finer scale would also be necessary.
\end{abstract}

\section{Background}

Tick-borne encephalitis (TBE) is the most important flavivirus infection of the central nervous system in Europe and Russia. The annual number of cases is estimated to be as high as 10,000 in Russia and about 3,000 in European countries [1-5]. Severe TBE infections caused by European virus strains typically take a biphasic course: After a short incubation period (usually 7-14 days, with extremes of 4-28 days), the first (viraemic) phase presents as an uncharacteristic influenza-like illness lasting 2-4 days (range 1-8 days) with fever,

\footnotetext{
* Correspondence: ckiffne@gwdg.de

'Department of Forest Zoology and Forest Conservation incl. Wildlife Biology and Game Management, Büsgen-Institute, Georg-August-University

Göttingen, Büsgenweg 3, 37077 Göttingen, Germany

Full list of author information is available at the end of the article
}

malaise, headache, myalgia, gastrointestinal symptoms, leukocytopenia, thrombocytopenia and elevated liver enzymes, and is often followed by a symptom-free interval of about one week (range 1-33 days). The second phase of TBE occurs in 20-30\% of infected patients and is marked by four clinical features of different severity (meningitis, meningoencephalitis, meningoencephalomyelitis or meningoencephaloradiculitis) and the appearance of specific antibodies in the serum and cerebrospinal fluid. This is usually the time when patients with high fever and severe headache seek medical advice. The fatality rate in adult patients is less than $2 \%$. However, severe courses of TBE infection with higher mortality and long-lasting sequelae, often affecting the patient's quality of life, are correlated with increased age [6-9].

C Biomed Central

(c) 2010 Kiffner et al; licensee BioMed Central Ltd. This is an Open Access article distributed under the terms of the Creative Commons Attribution License (http://creativecommons.org/licenses/by/2.0), which permits unrestricted use, distribution, and reproduction in any medium, provided the original work is properly cited. 
As with most zoonotic diseases [10], TBE incidence in humans is characterised by considerable temporal (Figure 1) and spatial (Figure 2) heterogeneity [11]. The main determinant of infection risk is the density of infected ticks, i.e. the product of pathogen prevalence in the ticks and tick density [12]. Ixodes ricinus, the main vector of TBE virus (TBEV), has three distinct stages, larval, nymphal and adult ticks [13] whereas nymphs are responsible for the majority of tick bites in humans [14]. The prevalence of TBEV in (nymphal) ticks depends on a combination of factors; the basic reproduction number $\left(R_{0}\right)$ of TBEV, which crucially depends on the occurrence of non-viraemic virus transmission between ticks co-feeding, especially on forest rodents [15-17]. Furthermore, the persistence of TBEV depends on a threshold value between the density of competent (e.g. yellownecked mice Apodemus flavicollis) and incompetent hosts (e.g. red deer Cervus elaphus) [18]. Possibly resulting from the species-specific reservoir competence, peaks in rodent populations in a given year are positively correlated with TBE incidence in humans in the succeeding year [19]. Co-feeding of larval and nymphal ticks on rodents critically depends on seasonal activity synchrony of these immature tick stages. Since Randolph et al.'s study [20], which related larval and nymphal synchrony to a certain temperature regime in autumn, subsequent research attention has been directed towards a specific temperature regime during spring time [11] causing the seasonal synchrony of immature ticks. Tick density in a given landscape is primarily determined by the availability of suitable forest habitat [21]. The findings of Allan et al. [22], relating to Lyme borreliosis risk, suggest that forest fragmentation might affect epidemiological risk. Tick density is further influenced by the abundance of host species such as roe (Capreolus capreolus) and red (Cervus elaphus) deer $[23,24]$ which feed large numbers ticks in all stages of

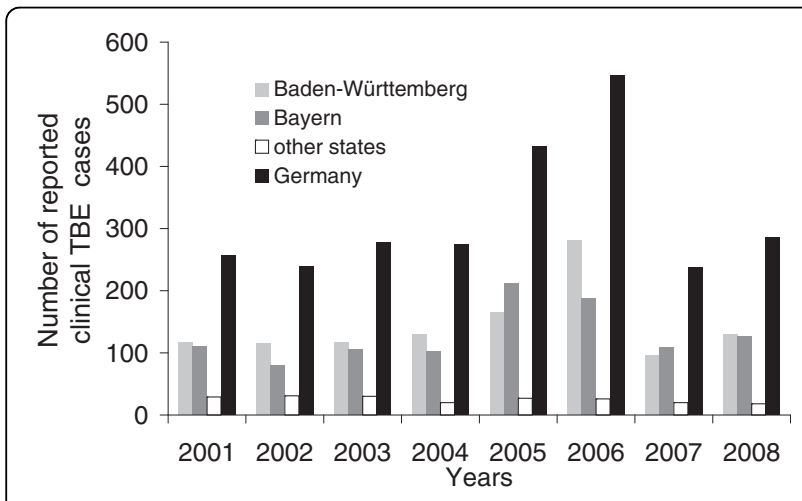

Figure 1 Number of reported human TBE infections in Germany from 2001-2008. Data source: Robert-Koch Institut: SurvStat, http://www3.rki.de/SurvStat. Accessed: 2/04/2009. development $[25,26]$. Since estimates of wildlife population densities do not exist at the appropriate temporal and spatial resolution, we used hunting bag statistics as proxy for density. We also used hunting bag data of red fox (Vulpes vulpes), which was found to be positively correlated (with a time lag of one year) with TBE incidence in humans in Sweden [27]. The explanatory variables investigated in this paper include hunting bag data for red deer, roe deer and red fox, land cover, spring warming increase, and an index of forest fragmentation. Specifically we apply statistical tests, which take account of spatial correlation, to assess whether these factors are related to TBE incidence in humans.

\section{Methods}

\section{Dependent variable}

Annual symptomatic TBE infections in humans registered by the patients' place of permanent residence (county level) for the period 2001-2008 were obtained from the data base of the Robert Koch-Institut (SurvStat, http://www3.rki.de/SurvStat, 11/02/2009). We included the human population size for each county and year (provided by the federal statistical bureau) in our model. For a given county in a given year we modelled $p$, the proportion of reported clinical TBE cases $y$ out of $n$ inhabitants, assuming that TBE incidence in humans and infection risk are closely correlated.

\section{A model for the TBE-count data}

Since our dependent variable consists of counts of successes $(y)$ and failures $(n-y)$ in $n$ trials, we used a generalized linear model (GLM) with binomial error distribution, i.e. a logistic regression model [28]. The statistical package $R$ [29] was used to estimate parameters of the model and to compute the test statistics. We model the probability that a person in a given county, and in a given year, is infected as a function of the explanatory variables.

\section{Explanatory variables}

\section{Forest type and forest cover}

Information on forest type and forest cover for each county was obtained from the CORINE dataset with a spatial resolution of 100 meters [30]. We used the most recent available land cover information (year 2000) for all years, assuming that forest type and cover did not change substantially over this relatively short time period. For each county, we computed the proportion of coniferous, broad-leafed and mixed forest area.

\section{Forest fragmentation}

Given the relative coarse resolution of the CORINE dataset, we used the 'largest patch index' (largest forest patch/total forest area) to approximate the level of forest fragmentation for each county [31]. 


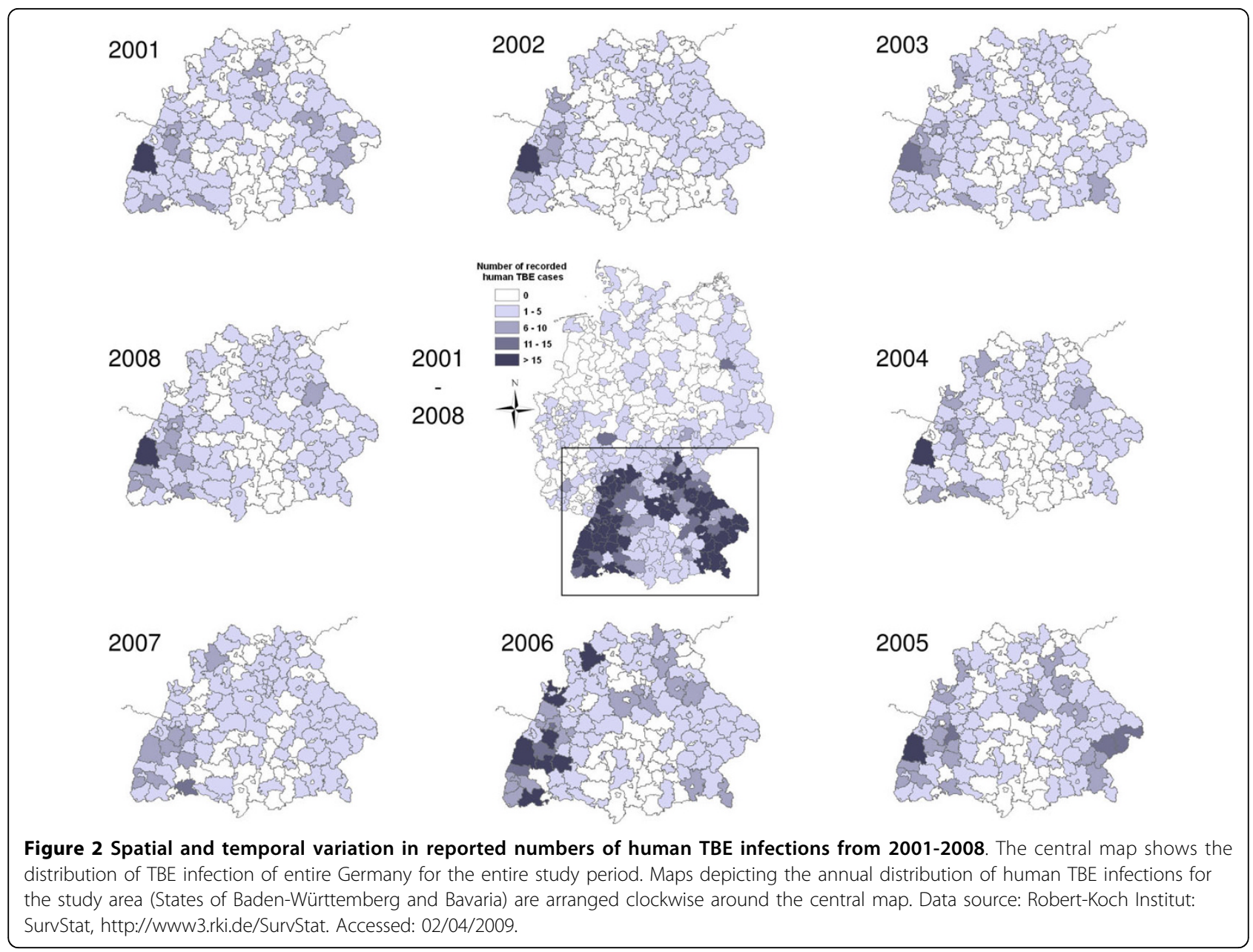

\section{Spring warming}

We extracted mean diurnal monthly interpolated temperatures from 30 arc $s$ resolution climate surface maps based on the 1950-2000 period [32]. These data describe the spatial variation of temperatures which seems reasonable for our research question, given that temporal variation of temperatures is unlikely to explain the temporal variation of TBE incidence $[33,34]$. Data preprocessing included a validity check of the temperature data and a re-projection to the WGS84 cartographic system in GIS ArcView version 9 (ESRI, Redlands, CA, USA). Mean interpolated temperatures $\left(\right.$ in ${ }^{\circ} \mathrm{C}$ ) were computed for each county, for the months of January, February, March and April. From these we computed the temperature increase in spring as the mean temperature increase between February and April corrected for the mean temperature of January [11].

\section{Hunting bag data}

We obtained annual hunting statistics of game species from wildlife authorities of both states (BadenWürttemberg and Bavaria) for the period 2000/2001$2007 / 2008$. To deal with the unequal sizes of the 140 counties, we standardised the hunting bag counts by dividing them by area available for wildlife, the latter being approximated by the area covered by agriculture and forest. For Bavaria, hunting bag data on roe deer were not available for the period 2000/2001. Considering the minor temporal variation in roe deer hunting bags, we used the roe deer bag data of the period 2001/ 2002 also for the missing period. In Bavaria, roe deer hunting is based upon a three years management plan but hunting bags are approximately evenly realised among years. In Baden-Württemberg, roe deer hunting is based on yearly management plans. Management plans for carnivores are not in place.

\section{Unexplained spatial and temporal variation}

Spatial autocorrelation [35] was incorporated by using the proportion of TBE cases per inhabitant in the neighbouring counties as an explanatory variable in the model. To control for unexplained temporal variation, we included each year as fixed factor (with year 2001 as reference) in the model. Summary statistics of dependent and explanatory variables are provided in Table 1. 
Table 1 Summary statistics of dependent and explanatory variables for a model explaining the spatio-temporal variation of tick-borne encephalitis in southern Germany from 2001-2008

\begin{tabular}{|c|c|c|c|c|}
\hline Dependent variable & Mean & SD & Min. & Max. \\
\hline Number of reported TBE infections in humans & 1.95 & 3.26 & 0.00 & 39.00 \\
\hline County population size (in units of 10,000 ) & 16.54 & 14.10 & 2.86 & 131.20 \\
\hline \multicolumn{5}{|l|}{ Explanatory variables } \\
\hline \multicolumn{5}{|l|}{ Proportion of forest cover/county } \\
\hline Broad-leafed forest & 0.05 & 0.06 & 0 & 0.28 \\
\hline Coniferous forest & 0.18 & 0.13 & 0 & 0.56 \\
\hline Mixed forest cover & 0.09 & 0.07 & 0 & 0.36 \\
\hline \multicolumn{5}{|l|}{ Forest fragmentation } \\
\hline Connectivity (largest forest patch/entire forest cover) & 0.19 & 0.14 & 0 & 0.74 \\
\hline \multicolumn{5}{|l|}{ Hunting bag in previous year per $\mathrm{km}^{2}$ hunting area } \\
\hline Red deer Cervus elaphus & 0.09 & 0.30 & 0 & 6.77 \\
\hline Roe deer Capreolus capreolus & 4.46 & 1.30 & 0.76 & 10.10 \\
\hline Red fox Vulpes vulpes & 2.17 & 0.91 & 0 & 17.86 \\
\hline \multicolumn{5}{|l|}{ Climatic variables } \\
\hline Spring warming: Temperature increase from February-April $\left({ }^{\circ} \mathrm{C}\right)$ corrected for mean January temperature & 9.25 & 1.39 & 6.07 & 12.59 \\
\hline \multicolumn{5}{|l|}{ Unexplained spatial variation } \\
\hline Total human TBE cases in all neighbouring counties per inhabitants of those counties & 0.00013 & 0.00014 & 0 & 0.00091 \\
\hline \multicolumn{5}{|l|}{ Unexplained temporal variation } \\
\hline Each year was entered as a fixed factor in the model & $-/-$ & $-/-$ & $-/-$ & $-/$ \\
\hline
\end{tabular}

Note that the hunting bag of roe deer in the counties of Bavaria is the average annual offtake of three years.

\section{Modelling procedure}

Before fitting a full model, we tested the effect of single covariates on the probability of TBE infections in humans after correcting for unexplained spatial and temporal variation (Table 2). We tested for multicollinearity between the explanatory variables (Table 3 ) by computing the condition number. For model checking the deviance residuals were computed and displayed using GRASS GIS [36].

\section{Results}

\section{Preliminary analyses}

After correcting for unexplained spatial and temporal variation, five of the eight candidate variables were significantly $(\mathrm{p}<0.05)$ related with TBE incidence in humans (Table 2). The candidate variables showed rather weak correlations, resulting in a condition number of 6.5, which indicates that multicollinearity is not of concern [37]. The final model was fitted using all candidate variables.

\section{Full model}

The full model suggested that all candidate variables were significantly associated with TBE infection risk in humans (Table 4). The proportion of forest cover was positively correlated with probability of TBE infection; the effect of coniferous forest cover was stronger than that of broad-leafed and mixed forest cover (Figure 3ac). When tested on its own, the proportion of broadleafed forest cover was not significant (Table 2).

TBE risk was significantly negatively associated with the forest fragmentation index. This suggests that,

Table 2 Relationships between single variables and the probability of tick-borne encephalitis infections in humans after correcting for spatial autocorrelation and unexplained temporal variation as tested by a logistic regression model

\begin{tabular}{|c|c|c|}
\hline Parameter & Algebraic sign of coefficient estimate & Significance level \\
\hline Proportion broad-leafed forest & - & 0.10 \\
\hline Proportion coniferous forest & + & $<0.001$ \\
\hline Proportion mixed forest & + & $<0.001$ \\
\hline Connectivity & + & 0.59 \\
\hline Red deer hunting bag & + & $<0.01$ \\
\hline Roe deer hunting bag & + & $<0.001$ \\
\hline Red fox hunting bag & - & 0.24 \\
\hline Spring warming & - & $<0.001$ \\
\hline
\end{tabular}


Table 3 Correlation matrix (Pearson product-moment correlation coefficient) between variables potentially explaining the probability of tick-borne encephalitis infections in humans in southern Germany

\begin{tabular}{|c|c|c|c|c|c|c|c|}
\hline Parameter & $\begin{array}{l}\text { Proportion broad- } \\
\text { leafed forest }\end{array}$ & $\begin{array}{c}\text { Proportion } \\
\text { coniferous forest }\end{array}$ & $\begin{array}{l}\text { Proportion } \\
\text { mixed forest }\end{array}$ & $\begin{array}{l}\text { Largest forest } \\
\text { patch index }\end{array}$ & $\begin{array}{c}\text { Red deer } \\
\text { hunting bag }\end{array}$ & $\begin{array}{c}\text { Roe deer } \\
\text { hunting bag }\end{array}$ & $\begin{array}{c}\text { Red fox } \\
\text { hunting bag }\end{array}$ \\
\hline $\begin{array}{l}\text { Proportion } \\
\text { coniferous forest }\end{array}$ & -0.53 & & & & & & \\
\hline $\begin{array}{l}\text { Proportion mixed } \\
\text { forest }\end{array}$ & 0.33 & -0.11 & & & & & \\
\hline $\begin{array}{l}\text { Largest patch } \\
\text { index }\end{array}$ & -0.13 & 0.17 & -0.15 & & & & \\
\hline $\begin{array}{l}\text { Red deer hunting } \\
\text { bag }\end{array}$ & -0.09 & 0.27 & 0.14 & -0.06 & & & \\
\hline $\begin{array}{l}\text { Roe deer hunting } \\
\text { bag }\end{array}$ & -0.03 & 0.06 & 0.21 & -0.34 & -0.07 & & \\
\hline $\begin{array}{l}\text { Red fox hunting } \\
\text { bag }\end{array}$ & 0.20 & -0.17 & 0.13 & -0.17 & -0.06 & 0.12 & \\
\hline Spring warming & -0.44 & 0.32 & -0.33 & -0.16 & 0.16 & -0.02 & -0.38 \\
\hline
\end{tabular}

taking all other variables as fixed, TBE risk in humans would decline if forest cover were more continuous (Figure 3d). Admittedly, we did not detect a significant relationship between the forest fragmentation index and TBE risk if tested without other explanatory variables (Table 2).

Wildlife population densities (measured indirectly as described above) were significantly correlated with TBE risk in humans in the following year (Figure 3e-g). The correlation with roe deer density was positive but those with red fox and red deer were negative. Except in the case of red deer, all coefficients in the full model have

Table 4 Parameter estimates of variables derived from the full logistic regression model aiming at explaining the spatio-temporal variation in human tick-borne encephalitis infections in southern Germany from 20012008

\begin{tabular}{lccc}
\hline Parameter & Estimate & Standard error & z-value \\
\hline Intercept & $-11.94^{* * *}$ & 0.32 & -37.30 \\
Proportion broad-leafed forest & $2.21^{* * *}$ & 0.47 & 4.71 \\
Proportion coniferous forest & $4.38^{* * *}$ & 0.23 & 18.69 \\
Proportion mixed forest & $3.21^{* * *}$ & 0.32 & 10.04 \\
Largest patch index & $-0.58^{* *}$ & 0.21 & -2.76 \\
Red deer hunting bag & $-0.27^{*}$ & 0.11 & -2.74 \\
Roe deer hunting bag & $0.21^{* * *}$ & 0.02 & 10.42 \\
Red fox hunting bag & $-0.21^{* * *}$ & 0.04 & -4.97 \\
Spring warming & $-0.14^{* * *}$ & 0.02 & -6.09 \\
Spatial autocorrelation & $817.75^{* * *}$ & 211.47 & 3.87 \\
Year 2002 & -0.16 & 0.10 & -1.63 \\
Year 2003 & -0.02 & 0.10 & -0.18 \\
Year 2004 & -0.09 & 0.09 & -0.98 \\
Year 2005 & $0.42^{* * *}$ & 0.08 & 4.92 \\
Year 2006 & $0.64^{* * *}$ & 0.08 & 7.81 \\
Year 2007 & $-0.30^{* *}$ & 0.10 & -2.93 \\
Year 2008 & -0.01 & 0.09 & -0.13 \\
\hline
\end{tabular}

(**P-value $<0.001 ;{ }^{* * P}$-value $<0.01 ; *$ P-value $\left.<0.05\right)$. the same sign as those in the corresponding restricted models. TBE risk was significantly correlated with temperature increase during the spring months (Figure $3 \mathrm{~h}$ ) both in the restricted and in the full model (Tables 2, 4). Unexpectedly, the correlation is negative.

There is strong evidence of spatial autocorrelation (Figure 3i) and, unfortunately, also of unexplained temporal heterogeneity. The incidence of TBE infections varied substantially from year to year (see Figure 1) peaking in 2005 and 2006. Of course we would have wished that the model could explain these peaks in terms of the explanatory variables considered here. As is evident in Table 4 we were unable to account for this temporal heterogeneity with the covariates available to us.

With the above limitations in mind, the model (Null deviance $=3580.0$ on 1119 degrees of freedom; residual deviance $=2494.8$ on 1101 degrees of freedom) explained a large fraction of the observed variance (CoxSnell- $R^{2}=0.96$, Nagelkerke's $R^{2}=0.65$ ). A histogram of the deviance residuals of the model (Figure 4) indicates that the distribution of the residuals is somewhat skewed, which is due to the discrete nature of the response; about $40 \%$ of the observed counts are equal to zero, and almost $75 \%$ of them are two or less. The spatial distribution of the residuals (Figure 5) varied considerably from year to year. There was a slight tendency to underestimate the TBE incidence in counties with few reported cases (south central part of the study area) and to overestimate the incidence in counties with many reported cases (western, northern and eastern regions of the study area) (Figures 2 and 5).

\section{Discussion}

The model explaining TBE incidence in southern Germany contains eight variables (three related to forest cover, one related to forest fragmentation, three related 
a)

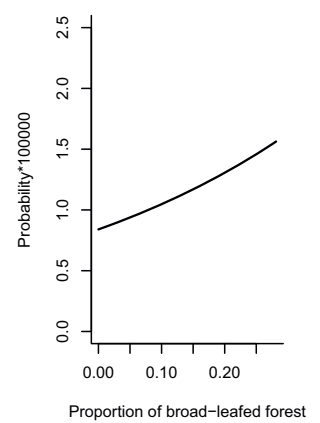

f)

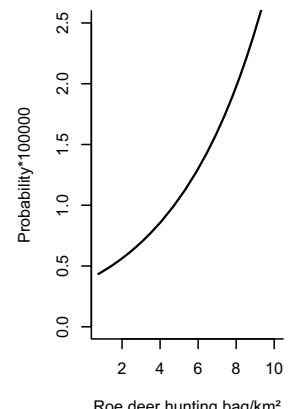

b)

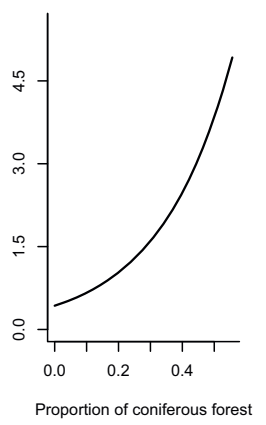

g)

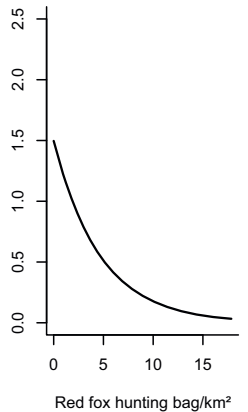

c)

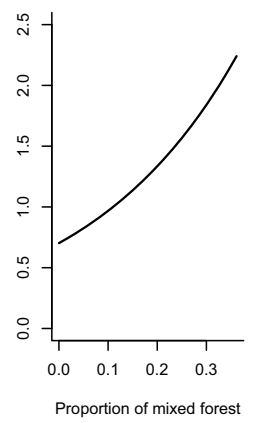

h)

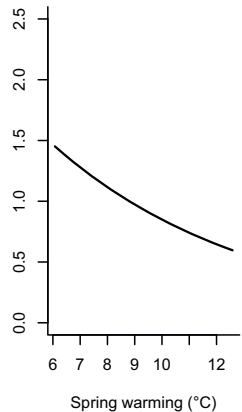

d)

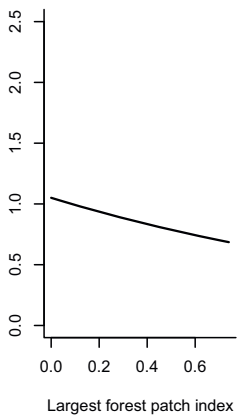

i)

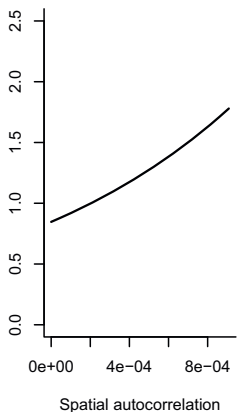

e)
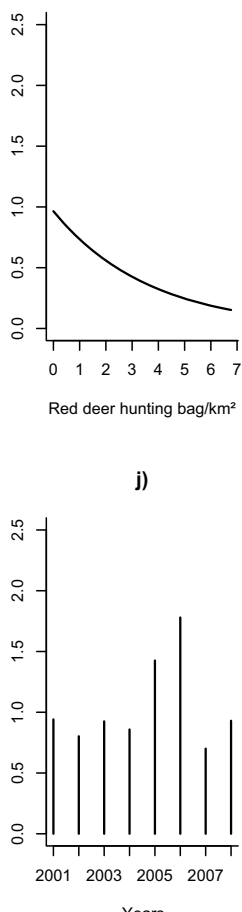

Figure 3 Relative effects of significant variables of the final model explaining the variation of human TBE infections in southern Germany. The effect of single variables on the probability of TBE incidence was estimated by predicting the full model on the entire range of the target variable. Non-target variables entered the model prediction with their mean value and using the year 2001 as reference. For a definition of the variables shown in a) - j), see Table 1.

to wildlife species population dynamics and one related to climatic conditions during spring time) plus one variable each to account for unobserved spatial and temporal variation. With one exception (spring warming) the results are broadly in line with previous research, highlighting the range of factors influencing TBE transmission dynamics and thus infection potential in humans $[33,34,38]$. The fact that the factor "year" had to be included in the model constitutes a failure of the model. Other factors, especially those taking account of human activities, would need to be considered to explain the remaining and substantial temporal

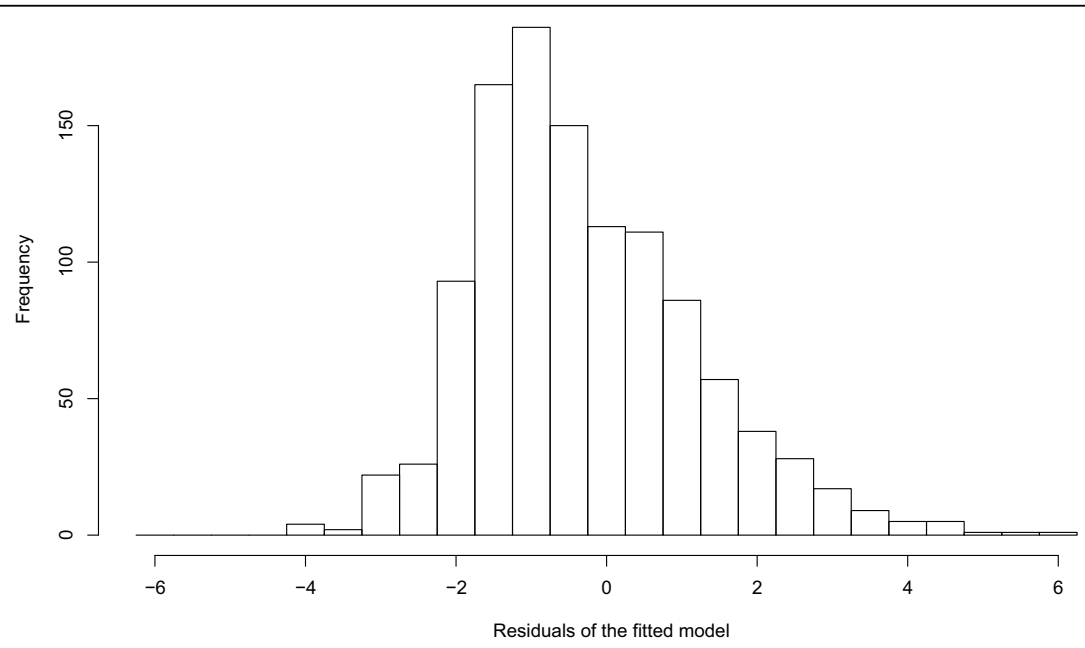

Figure 4 Histogram of the residuals of the final model explaining the variation of human TBE infections in southern Germany. 


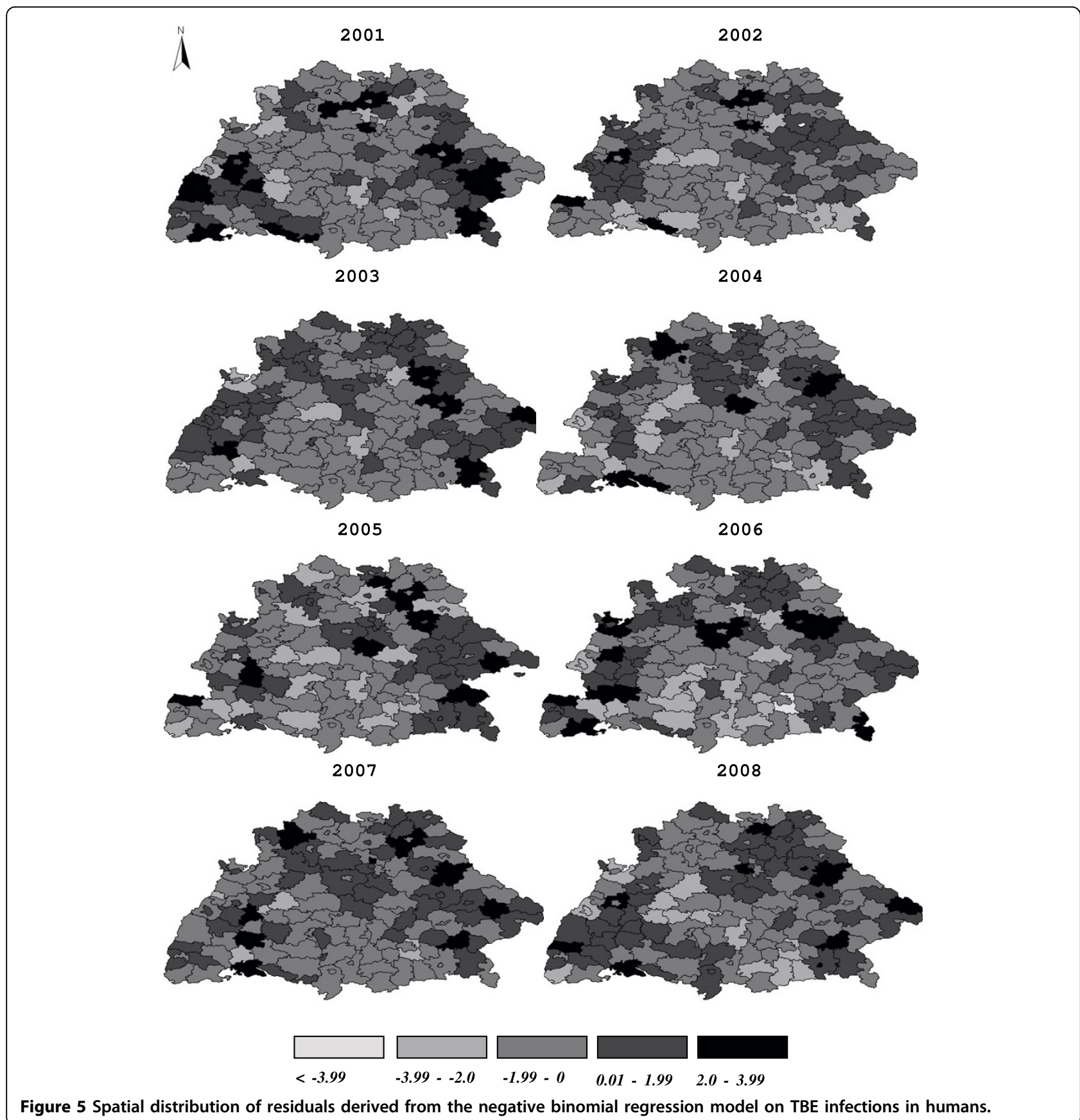

heterogeneity. The admittedly incomplete model does, however, consider the influence of several explanatory variables simultaneously, rather than one variable or a few variables.

The proposed model suggests that the proportion of coniferous forests had a stronger effect on TBE risk for humans compared to other forest types. Results from field studies provide equivocal results concerning the epidemiological risk [densities of (infected) ticks] according to forest type, but generally broad-leafed forest is considered as a suitable habitat for ticks. In North American forests, black-legged ticks (Ixodes scapularis) are more abundant in deciduous than in coniferous woodlands [39]. In Scotland, tick densities were highest in coniferous forests compared to deciduous woodland and pastures [40]. In Denmark, no differences in Ixodes ricinus tick densities between spruce (conifer) forests and non spruce forests were found [23]. It is, however, unlikely that forest type itself accounts directly for tick density patterns. Potentially, forest type 
indirectly affects tick densities by providing appropriate moisture and host species for ticks or by sustaining more TBE competent reservoir species relative to incompetent ones $[18,23,33]$, or forest types are unevenly frequented by humans.

In addition to forest extent, we hypothesized that forest fragmentation would enhance TBE risk either by increasing density of infected ticks [22] or by enhancing contact rates between humans and ticks. The effect of forest fragmentation was unclear. Despite showing weak correlations with other variables (Table 3 ), which indicates that it is not confounded with other variables, the sign of the coefficient in the simple model was the opposite of that in the full model. Yet, removing this variable from the full model did not alter the signs of other coefficients.

Hunting bag densities of three game species were found to be significantly associated with TBE risk in humans. Since hunting bags are subject to management plans (deer) and/or influenced by hunting effort (red fox), these observations should be regarded cautiously [41]. Yet, "important ecological questions simply have to be addressed on the right scale - which often means an uncomfortable large scale - even if that means a certain degree of imprecision" [42]. There is growing empirical evidence that roe deer populations increase the epidemiological risk of ticks [23], Lyme disease risk [43] and TBE risk [[33], [44], this study]. Regarding the role of red deer in determining TBE risk, our results are inconclusive (changing signs simple model vs. full model) but do not necessarily contradict findings from Italy, where a non-significant effect was found between red deer and TBE incidence in humans [33].

The negative relationship found in this study between red fox hunting bags and human TBE cases in the succeeding year is in contrast to a study in TBE endemic areas in Sweden, where this relationship was found to be positive [27]. These contradictory findings will need to be clarified in future studies on the specific role of foxes in the epidemiology of TBEV.

Unfortunately, reliable data on forest rodent dynamics are not available at the appropriate temporal and spatial scale, and could thus not enter our model. Further attempts should be made to test the hypothesis that high rodent (especially Apodemus flavicollis) densities translate into high nymphal densities in the following year [45] and hence to elevate TBE incidence in humans [19]. Such a finding might be of use as an effective early warning system for public health.

Unexpectedly, the direction of the regression coefficient of the spring warming variable is not in line with the claimed importance of simultaneous activity of larval and nymphal ticks for TBE maintenance [11]. That theory suggests that fast warming in spring is required to allow nymphs (critical temperature $\sim 7^{\circ} \mathrm{C}$ ) and larvae (critical temperature $\sim 10^{\circ} \mathrm{C}$ ) to feed synchronously [16] and to transmit pathogens among the tick population [15]. However, it should be emphasised that spring warming has so far been used only to explain the distribution of TBE foci and not the variable incidence.

As in most epidemiological studies, we based our analysis on the assumption that TBE incidence is strongly correlated with the epidemiological risk of TBE (i.e. the density of infected nymphs). Although the model provides a reasonable fit, some potentially important factors were not investigated due to lack of data. Included here are differing virulence of TBE, variable exposure of humans to ticks, differing immune responses, demography and TBE immunisation coverage. E.g. Kimmig et al. [46] found discrepancies in spatial distribution of clinical TBE cases and prevalence of TBE antibodies in sera of persons at risk. In addition, demographic analyses indicate that men above the age of 35 years are disproportional represented (Figure 6) among the persons with clinical TBE symptoms, which might be related to higher exposure risk to ticks and/or to differing immune responses [47]. Furthermore, locations associated with the counts available to us are the patients' place of permanent residence, and not the place of infection. Although it is likely that most infections occur in the infected person's home county, exceptions in this respect are clearly a potential source of bias. Due to data availability this analysis is based on a rather coarse scale [cf. 42]. Counties do not necessarily represent homogenous units with respect to environmental and ecological conditions. Generally forests, animal communities and interpolated temperatures are very heterogeneous within a given county. Thus any analysis based on values that have been averaged over variable conditions cannot be expected to yield precise results.

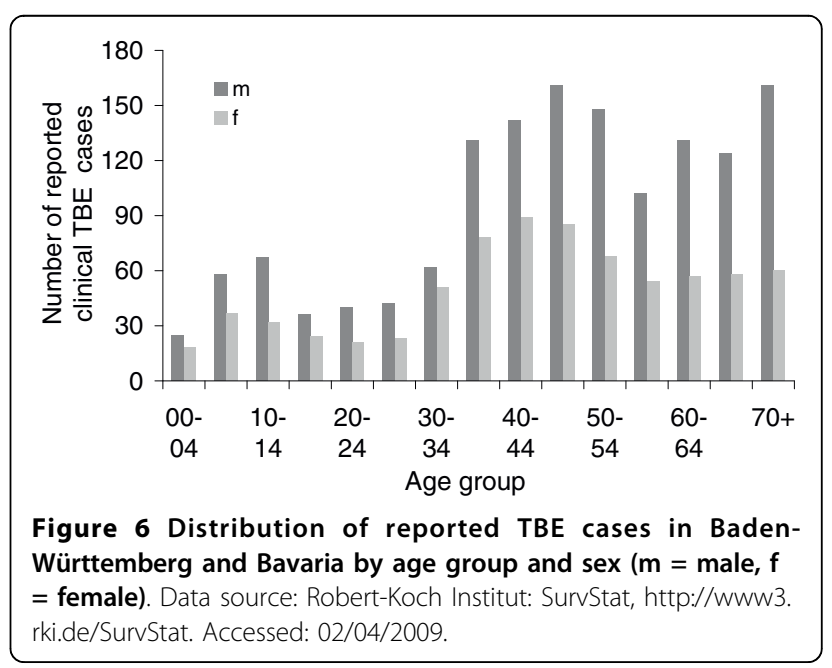


Consequential we strongly recommend recording the suspected places of TBE infection as accurately as possible i.e. at the resolution of the forest patch.

\section{Conclusions}

Our modelling approach focussed on ten biotic and abiotic factors possibly influencing the epidemiological risk of TBE. Except for the influence of spring warming, the results are in line with previously published findings. The presented approach might therefore be useful for predicting at least the potential direction, and approximate magnitude of TBE risk, as a function of ecological change (land cover change, wildlife population dynamics). To make further progress, a higher spatial resolution is needed in order to make more reliable interferences about the relationships between eco-environmental factors and TBE incidence. Moreover, neither this analysis nor the in-depth analyses of yearly temperature variability $[33,34,48]$ could entirely explain the temporal dynamics of tick abundance and TBE in the past decade. This underlines previous notions that besides the epidemiological risk, the contact rate probability between infected ticks and humans is of crucial importance and should be incorporated in models for tick-borne diseases $[11,43,48]$.

\begin{abstract}
Acknowledgements
This study was funded by a research grant from the Federal Ministry of Education and Research (BMBF grant 1363120: Emerging arthropod-borneviral infections in Germany: Pathogenesis, diagnostics and surveillance).The Bavarian State Ministry of Alimentation, Agriculture and Forestry and the Wildlife Research Unit of the State Baden-Württemberg kindly provided hunting bag data. Data on human population were kindly supplied by the German Federal Statistical Office. We sincerely thank F. Herschleb for assistance in digitalising hunting bag data and $\mathrm{H}$. Reinecke for generating the map of the residuals. We thank four anonymous reviewers whose comments greatly improved previous drafts of this manuscript.
\end{abstract}

\section{Author details}

${ }^{1}$ Department of Forest Zoology and Forest Conservation incl. Wildlife Biology and Game Management, Büsgen-Institute, Georg-August-University Göttingen, Büsgenweg 3, 37077 Göttingen, Germany. ${ }^{2}$ Institute for Statistics and Econometrics, Georg-August-University Göttingen, Platz der Göttinger Sieben 5, 37073 Göttingen, Germany. ${ }^{3}$ Centre for Biological Safety, Robert Koch-Institut, Nordufer 20, 13353 Berlin, Germany.

\section{Authors' contributions}

CK designed the experiment, acquired the data, performed the statistical analysis, interpreted the results and wrote the manuscript. WZ designed the experiment, performed the statistical analysis, contributed to the interpretation of the results and the writing of the MS. PS performed the GIS analyses. FR acquired the data, contributed to the interpretation of the results and the writing of the MS. TV, PH and MN contributed to the interpretation of the results and the writing of the MS. All authors read and approved the final manuscript.

\section{Competing interests}

The authors declare that they have no competing interests.

Received: 6 April 2010 Accepted: 13 August 2010

Published: 13 August 2010
References

1. Pugliese A, Beltramo T, Torre D: Emerging and re-emerging viral infections in Europe. Cell Biochem Funct 2007, 25(1):1-13.

2. Günther $G$, Haglund M: Tick-borne encephalopathies: epidemiology, diagnosis, treatment and prevention. CNS Drugs 2005, 19(12):1009-32

3. Charrel RN, Attoui H, Butenko AM, Clegg JC, Deubel V, Frolova TV, Gould EA, Gritsun TS, Heinz FX, Labuda M, Lashkevich VA, Loktev V, Lundkvist A, Lvov, Mandl CW, Niedrig M, Papa A, Petrov VS, Plyusin A, Randolph S, Süss J, Zlobin VL, de Lamballerie X: Tick-borne virus diseases of human interest in Europe. Clin Microbiol Infect 2004, 10(12):1040-55.

4. Gritsun TS, Lashkevich VA, Gould EA: Tick-borne encephalitis. Antiviral Res 2003, 57(1-2):129-46.

5. Süss J: Tick-borne encephalitis in Europe and beyond - the epidemiological situation as of 2007. Euro Surveill 2008, 13(26), pii=18916.

6. Holzmann H: Diagnosis of tick-borne encephalitis. Vaccine 2003, 21(Suppl 1):S36-40.

7. Kunze U, Baumhackl U, Bretschneider R, Chmelik V, Grubeck-Loebenstein B, Haglund M, Heinz F, Kaiser R, Kimmig P, Kunz C, Kunze M, Mickiene A, Misic-Majerus L, Randolph S, Rieke B, Stefanoff P, Süss J, Wimmer R, International Scientific Working Group on Tick-borne encephalitis: The Golden Agers and Tick-borne encephalitis: Conference report and position paper of the International Scientific Working Group on Tickborne encephalitis. Wiener Med Wochenschr 2005, 155(11-12):289-94.

8. Kaiser R: Tick-borne encephalitis (TBE) in Germany and clinical course of the disease. Int J Med Microbiol 2002, 291(Suppl 33):58-61.

9. Mickiene A, Laiskonis A, Günther G, Vene S, Lundkvist A, Lindquist L: Tickborne encephalitis in an area of high endemicity in Lithuania: disease severity and long-term prognosis. Clin Infect Dis 2002, 35(6):650-658.

10. Jones E, Patel NG, Levy MA, Storeygard A, Balk D, Gittleman JL, Daszak P: Global trends in emerging infectious diseases. Nature 2008, 451:990-994.

11. Randolph SE, Sumilo D: Tick-borne encephalitis in Europe: dynamics of changing risk. Emerging Pests and Vector-borne Diseases in Europe Wageningen, University PublishersTakken W, Knols B 2007, 187-206.

12. Ostfeld RS, Canham CD, Oggenfuss K, Winchcombe RJ, Keesing F: Climate, deer, rodents, and acorns as determinants of variation in Lyme-disease risk. PLOS Biol 2006, 4(6):e145.

13. Randolph SE: Tick ecology: processes and patterns behind the epidemiological risk posed by ixodid ticks as vectors. Parasitology 2004, 129(Suppl 1):S37-S65.

14. Vassalo M, Perez-eid C: Comparative behavior of different life cycle stages of Ixodes ricinus (Acari: Ixodidae) to human-produced stimuli. J Med Entomol 2002, 39:234-236.

15. Labuda M, Nuttal PA, Kozuch O, Eleckova E, Zuffova E, Sabo A: Nonviraemic transmission of tick-borne encephalitis virus: a mechanism for arbovirus survival in nature. Experientia 1993, 49:802-805.

16. Randolph SE, Gern L, Nutall PA: Co-feeding ticks: Epidemiological significance for tick-borne pathogen transmission. Parasitol Today 1996, 12(12):472-479.

17. Hartemink NA, Randolph SE, Davis SA, Heesterbeek : The basic reproduction number for complex disease systems: defining $\mathrm{R}_{0}$ for tickborne infections. Am Nat 2008, 171(8):743-754.

18. Rosà R, Pugliese A: Effects of tick population dynamics and host densities on the persistence of tick-borne infections. Math Biosci 2007, 208:216-240.

19. Zeman $P$, Benes $C$ : A tick-borne encephalitis ceiling has moved upwards during the last 30 years: possible impact of global warming? Int J Med Microbiol 2004, 293(Suppl 37):48-54.

20. Randolph SE, Green RM, Peacey MF, Rogers DJ: Seasonal synchrony: the key to tick-borne encephalitis foci identified by satellite data. Parasitology 2000, 121:15-23.

21. Racz GR, Ban E, Ferenczi E, Berencsi G: A simple spatial model to explain the distribution of human tick-borne encephalitis cases in Hungary. Vector-Borne Zoonot 2006, 6:369-378.

22. Allan BF, Keesing F, Ostfeld RS: Effect of forest fragmentation on lyme disease risk. Conserv Biol 2003, 17(1):267-272.

23. Jensen PM, Hansen H, Frandsen F: Spatial risk assessment for Lyme borreliosis in Denmark. Scand J Infect Dis 2000, 32:545-550.

24. Gilbert L: Altitudinal patterns of tick and host abundance: a potential role for climate change in regulating tick-borne diseases? Oecologia 2010, 162:217-225. 
25. Kiffner C, Lödige C, Alings M, Vor T, Rühe F: Abundance estimation of Ixodes ticks (Acari: Ixodidae) on roe deer (Capreolus capreolus). Exp Appl Acarol 2010, 52:73-84.

26. Vor T, Kiffner $C$, Niedrig M, Hagedorn P, Rühe F: Tick burden on European roe deer (Capreolus capreolus L.). Exp Appl Acarol 2010, 51:405-417.

27. Haemig PD, Lithner S, Sjöstedt de Luna S, Lundkvist $\AA$, Waldenström J, Hansson L, Arneborn M, Olsen B: Red fox and tick-borne encephalitis (TBE) in humans: Can predators influence public health? Scand J Infect Dis 2008, 40:527-532

28. Dobson AJ, Barnett AG: An introduction to generalized linear models. Boca Raton, Chapman \& Hall/CRC 2008.

29. R Development Core Team: R: A language and environment for statistical computing. R Foundation for Statistical Computing, Vienna, Austria 2008 [http://www.R-project.org].

30. Anonymous: CORINE Land Cover. Federal Environmental Agency, German Aeospace Center 2004.

31. Haines-Young R, Chopping M: Quantifying landscape structure: a review of landscape indices and their application to forested landscapes. Prog Phys Rev 1996, 20:418-445.

32. Hijmans RJ, Cameron SE, Parra JL, Jones PG, Jarvis A: Very high resolution interpolated climate surfaces for global land areas. Int J Climat 2005, 25:1965-1978

33. Rizzoli A, Hauffe HC, Tagliapietra V, Neteler M, Rosà R: Forest structure and roe deer abundance predict tick-borne encephalitis risk in Italy. PloS ONE 2009, 4:e4336

34. Sumilo D, Asokliene L, Bormane A, Vasilenko V, Golovljova I, Randolph SE: Climate change cannot explain the upsurge of tick-borne encephalitis in the Baltics. PLOS ONE 2007, 6:e500.

35. Wimberly MC, Baer AD, Yabsley MJ: Enhanced spatial model for predicting the geographic distributions of tick-borne pathogens. Int J Health Geogr 2008, 7:15.

36. GRASS Development Team: Geographic Resources Analysis Support System (GRASS) Software,I 2010. Open Source Geospatial Foundation [http://grass.osgeo.org].

37. Mason CH, Perreault WD: Collinearity power and interpretation of multiple regression analysis. J Marketing Res 1991, 28:268-280.

38. Estrada-Pena A: Tick-borne pathogens, transmission rates and climate change. Front Biosci 2009, 14:2674-2780.

39. Ginsberg HS, Zhioua E, Mitra S, Fischer J, Buckley PA, Verret F, Underwood HB, Buckley FG: Woodland type and spatial distribution of nymphal Ixodes scapularis (Acari : Ixodidae). Environ Entomol 2004, 33(5):1266-1273.

40. Walker AR, Alberdi MP, Urquhart KA, Rose H: Risk factors in habitat of the tick Ixodes ricinus influencing human exposure to Ehrlichia phagocytophila bacteria. Med Vet Entomol 2001, 15:40-49.

41. Ranta $E$, Lindström J, Lindén $H$, Helle P: How reliable are harvesting data for analyses of spatio-temporal population dynamics? Oikos 2008, 117:1461-1468.

42. May RM: Crash test for the real. Nature 1999, 398:371-372.

43. Linard C, Lamarque P, Heyman P, Ducoffre G, Luyasu V, Tersago K, Vanwambeke SO, Lambin EF: Determinants of the geographic distribution of Puumala virus and Lyme borreliosis infections in Belgium. Int I Health Geogr 2007, 6:15.

44. Hudson PJ, Rizzoli A, Rosà R, Chemini C, Jones LD, Gould EA: Tick-borne encephalitis virus in northern Italy: molecular analysis, relationships with density and seasonal dynamics of Ixodes ricinus. Med Vet Entomol 2001, 15:304-313.

45. Rosà R, Pugliese A, Ghosh M, Perkins SE, Rizzoli A: Temporal variation of Ixodes ricinus intensity on the rodent host Apodemus flavicollis in relation to local climate and host dynamics. Vector-Borne Zoonotic Dis 2007, 285-295.

46. Kimmig P, Oehme R, Backe H: Epidemiologie der FrühsommerMeningoenzephalitis (FSME) und Lyme-Borreliose in Südwestdeutschland. Ellipse 1998, 14(4):95-105.

47. Sheldon BC, Verhulst S: Ecological immunology: costly parasite defences and trade-offs in evolutionary ecology. TREE 1996, 11:317-321.

48. Randolph SE, Asokliene L, Avsic-Zupanc T, Bormane A, Burri C, Gern L, Golovljova I, Hubalek Z, Knap N, Kondrusik M, Kupca A, Pejcoch M, Vasilenko $V$, Zygutiene M: Variable spikes in tick-borne encephalitis incidence in 2006 independent of variable tick abundance but related to weather. Parasites \& Vectors 2008, 1:44.
doi:10.1186/1476-072X-9-42

Cite this article as: Kiffner et al: Determinants of tick-borne encephalitis in counties of southern Germany, 2001-2008. International Journal of Health Geographics 2010 9:42.

\section{Submit your next manuscript to BioMed Central and take full advantage of:}

- Convenient online submission

- Thorough peer review

- No space constraints or color figure charges

- Immediate publication on acceptance

- Inclusion in PubMed, CAS, Scopus and Google Scholar

- Research which is freely available for redistribution 